\title{
The Sensory Value of Commodity: Homogenization and Differentiation of Pigs and Pork in Okinawa, Japan
}

\author{
Rima Higa \\ Japan Society for the Promotion of Science
}

This article examines the cultural meaning of food production in industrialized Okinawa, Japan, focusing on the commoditization of pigs and pork products. Commoditization manipulates sensory attributes such as colors, scents and textures for commercial purposes. The sensory values I discuss here relate to commercial value which manipulates sensory attributes such as colors, scents and textures. I describe ethnographically how pigs and pork are commoditized in a local pig farm and marketplace, and reveal the sensory aspects of food business. In the case of Okinawa, pigs and pork are regarded as one of the most important domestic animals and foods in the context of ritual as well as everyday life. This position is linked to the manipulation of the sensory qualities today. The purpose of this article is, through an analysis of the cultural codes behind sensory manipulation, to forward an anthropological understanding of this food business in its local context.

\section{INTRODUCTION}

This article examines the cultural meaning of food production in industrialized Okinawa, Japan, focusing on the commoditization of pigs and pork products. The main concern is the commoditization process of pigs and pork. Commoditization manipulates sensory attributes such as colors, scents and textures for commercial purposes. Thus, this paper explores the linkages between commercial value, the production of the most desirable and so marketable product, and somatic values apprehended by the senses; that is attributes such as colors, scents and textures. I describe ethnographically how pigs and pork are commoditized in a local pig farm and marketplace, in order to reveal the sensory aspects of food business. I focus on how pigs and pork are judged by sight or smell and how theses sights and smells are manipulated in making a higher valued product aesthetically and so economically. Aesthetic-economic value is entwined with socio-cultural relationships and this project adds relevant and comparative insight to questions raised recently in the field of 'Anthropology of the senses'. As Cristina Grasseni stresses, 'recent literature on theoretically informed but practice-based anthropology of the senses remains so-far untapped' (Grasseni 2005: 91). 


\section{Anthropology of Food and Industrialization}

Recent studies in the anthropology of food focus on the impact of industrialization and examine the relationship between food industries and dietary patterns. Jack Goody was a pioneer in this area focusing on a macro-history of food industrialization (Goody 1982). In his research, he went back to the beginning of industrial revolution in England in the 18th century and divided industrial developments into four interrelated fields: preservation, mechanization, transport and retailing. Goody underscored how mass production and the mass distribution of industrial food lead to a homogenization of food consumption (Goody 1982: 170).

Some key studies have focused on the relationship between food and sensory perception (cf. Seremetakis 1994; Sutton 2001). For instance, Nadia Seremetakis depicts agricultural industrialization as a process which considerably reduces the taste and aroma of agricultural products in Greece (Seremetakis 1994). As a result, vanishing scents and flavors weaken the linkage of memory and food. According to her, consumers are deprived of the richness of their sensory experiences by mass-produced goods.

Seremetakis argues that there is a relationship between the senses and the homogenization of food products in industrial societies. In particular, her argument is remarkable in that the homogenizing processes cause an erosion of sensory perceptions. However, the matter is not quite as simple as she suggests. Indeed, others conversely call attention to the differentiation of goods by making full use of the senses (Classen et al. 1994; Rajagopal 1998; Green 2002; Grasseni 2003; Howes 2005).

In contrast to Seremetakis, these scholars of this ilk focus on an excess of the senses, which Howes conceptualizes as "hyperesthesia" (ibid: 288). In order to boost commercial value, food products are invested with multisensory qualities (Grasseni 2003; Howes 2005). In other words, the sensuality of a commodity is becoming a more important factor in defining commercial value. Giving an example of artificial flavor, some scholars noted that flavored foods are differentiated from scentless, tasteless mass-produced ones (Classen et al. 1994: 197-200; Howes 2005: 289).

Unlike Seremetakis, they point out that manipulating the sensory qualities boost the commercial value, but these arguments are problematic. As they focus too narrowly on product development in terms of marketing strategy, while they tend to neglect the cultural code behind it. For a fuller understanding, I expand my focus to include an analysis of the cultural significance underlying sensory value and link this to product development and marketing strategies.

The need for a socio-cultural analysis of food as commodity is apparent in the anthropological understanding of the food business. Sahlins emphasized the necessity of "a cultural account of production" (Sahlins 1976: 169). It is important for us to note meanings people give to things and the process of signification (cf. Ohnuki-Tierney 1997; Counihan 1999; Bestor 2001, 2004). Especially in his analysis of production, Sahlins argued how the meaningful relations in a symbolic system determine the value of commodity (ibid: 169-171). The cultural value of food goods should be understood from this point of view.

Accordingly, this article reveals how the sensory value of pigs and pork as a commodity is governed by the cultural code of Okinawa, Japan. In considering the industrialization of swine production, I investigate the dynamics of both the homogenization and the differentiation of pigs and pork as a commodity. The purpose of this article is, through an analysis of the cultural codes behind sensory manipulation, to outline an anthropological understanding of the food business in a local context. In the case of Okinawa, people regard pigs and pork as one of the most important domestic animals and foods in the context of ritual as well as everyday life. The perception is linked to the manipulation of sensory qualities in the present tense. 
The second section of this chapter is an overview of the history of pork production and distribution in Okinawa. It chronicles the effects of industrialization on pork, which is socioculturally and economically one of the most important foods in the postwar period on Okinawa. The third section argues that the efficient production and distribution of pork is grounded on the visual homogenization of the food product. This is one essential facet of industrialization in postwar Okinawa; a new grading institution that judges pork quality by their appearance alone. Such a system makes pork evaluation more efficient to expedite in commercial transactions. The fourth section demonstrates how sellers manipulate pork's multisensory qualities at the marketplace, the end of the chain. Pork products are differentiated by the sensorial value added. Finally, I discuss the sensory aspects of the food business; I discuss cases of homogenization and differentiation in the production of pigs and pork and the sensory aspects underlying the food retail business.

\section{Methodology}

My research was based on fieldwork at a pig farm and at a marketplace situated in mainland Okinawa in the southwestern islands of Japan. It was carried out over a period of about eighteen months between 2003 and 2009. At the pig farm, which is situated in northern area of Okinawa Island, there are eleven employees breeding and rearing pigs. They keep about 8000 pigs and sell about 800 head a month in markets both inside and outside the island. I went through training for new recruits and learned how to manage a large number of pigs and practice artificial insemination and everyday chores.

The pork marketplace is located in an urban part of the island. In the location there are one hundred and fifteen shops, and more than half of them sell foodstuffs. Ten of them sell meat and seven of the ten specialize in pork. Most pork shops are family-run, usually by a husband and a wife. Mainly, I did a fieldwork at three family-operated pork butchers. During New Years' holiday and Bon Festival in the lunar calendar, I conducted periodical participant observation, primarily assisting in the cutting of intestines, which are a popular foodstuff during these seasons. In addition, I visited two public slaughterhouses on the island, and interviewed workers and an inspector.

With the location of the farm and marketplace situated in the following section I will focus on the shift from small-scale pig husbandry to industrialization.

\section{THE SHIFT FROM SMALL-SCALE PIG HUSBANDRY TO INDUSTRIALIZATION}

\section{Small-Scale Pig Husbandry in the Past}

On the island, people used to domesticate a variety of animals to use for traction in cultivation and for meat. The domestication of swine just started from the end of 14 th to 15 th centuries and flourished by the middle of 18th century. Before the Second World War, the island's pig population was the highest in Japan (Kinjo 1987: 18-22).

However, a large number of pigs were killed during the Second World War and the domestic pork-producing system was destroyed. The number of indigenous pigs estimated to have survived is about 850 head on mainland Okinawa and about 1200 head on the outer Ryukyu Islands (Yoshida 1983: 42). During the Occupation of Japan the US Military Government implemented measures to increase production (Ryukyu Seifu Bunkyokyoku 1988: 4-8). It imported gilt, sow and boar from the US not to be utilized for food but for propagation purposes they also enacted regulations regarding the slaughtering of hogs (Toyama 1979: 114; Okinawa- 
ken Norin Suisan Gyoseishi Henshu Iinkai 1986: 255-256). In this way, the foundations of the pig husbandry system were rebuilt in the decade after the war.

Most households made their living by farming. Pigs were kept for meat and to assist in composting (Shimabukuro 1989; Komatsu 2007; Hagiwara 1995, 2009). People fed and slaughtered one or a few pigs for a year for the Lunar New Year. This domestic consumption was embedded in the "wä-kurushi" -or "pig-killing"- ritual where local people became skilled in slaughtering and butchering.

During the pig-killing ritual, people used to eat pork and tripe soup called nakami-jiru and preserved the rest with salt $(s \bar{u}$-chiki). Salting was a preserving technique before the introduction of refrigeration. The meat was salted for about half a year until the busy farming season in May. During this busy season salt pork was only eaten during ceremonial events or in exchange, that is to say as payment for the co-operative work such labor intensive farming required. In this way, salting was a technique used to preserve pork for domestic use.

\section{Industrialization of Pig Production Since 1970s}

"Restoring the prewar system" (Ryukyu Seifu Bunkyokyoku 1988: 4-8) was not meant exactly in a literal sense, but in fact it led to take a step toward industrialization. That is, postwar re-construction brought about fundamental structural changes to pig production and pork consumption. During industrialization, refrigerating technology was introduced which enabled distribution over broader areas and pork is no longer embedded in the subsistence economy but repositioned in the market economy. Because of this, salting as preserving technique was abandoned. In the post-war period, salted pork as well as meat and tripe soup became valuable foods associated with rituals.

As the pig production system developed and stabilized, people stopped raising and slaughtering one or two pigs for their own use or for a small-amount of cash. Specialization added a new production system based on a division of labor. Because of further specialization, people no longer kept their own pigs, and thus, had to buy pork as a finished product. In other words, the majority of Okinawan people became consumers, not producers, who buy the end product in stores. Salaried workers fed pigs in secluded, confined facilities and slaughtered them in a government run abattoir. There are two public abattoirs on mainland Okinawa, and the slaughtering and primary processing is the exclusive purview of legally regulated slaughterhouses. In addition, wholesalers have reorganized the established pork distribution chain and adjusted its pivotal role in product flow. At the end of the downstream market, newand old-fashioned retailers engage in the final commoditization of this foodstuff. This is the way that a system based on a division of labor was firmly established.

These processes of specialization were supported by advancements in mechanization. For example, the new-type pig farm set up automatic self-feeders and watering devices, which automated some of the industry's daily time consuming chores. The slaughterhouse, installed a highly mechanized and partially automated production line, that enhanced the capability and capacity of slaughtering and processing. In sum, both facilities were made increasingly automated and efficient.

It is notable that transportation and preserving technology developed rapidly after Okinawa's reversion from American rule to Japanese administration in 1972 (Okinawa-ken Norin Suisan Gyoseishi Henshu Iinkai 1986). In particular, progress in freezing and refrigerating transport technology led to a significant change in the way pork products were produced and distributed. It enabled the export and import of perishable foodstuffs with uncontaminated sanitary conditions 
to more remote areas. In a case of pork, this means that not the whole pig but parts of meat (pigs are cut into sections after slaughtering) could be vacuumed and shipped from the producing region (Higa 2008: 71-74). These interconnected developments accelerated the industrialization of pork production and distribution in postwar Okinawa.

As mentioned above, the process of postwar reconstruction caused the industrialization of pork production, distribution and consumption. This industrialization entails three great developments: the specialization based on division of labor; the mechanization of the workplace; and refrigerating transport technology. These interrelated advances allowed the mass-production and distribution of pork to broader areas than ever before. What is important however, is that these processes were promoted in parallel with the homogenization of pork as a commodity notably through sensory apparatus of vision.

\section{HOMOGENIZATION OF PIGS AND PORK BY VISION}

\section{The Pork Grading System as a Form of Visual Standardization}

In Okinawa, the establishment of a mass pig-producing system was accompanied by the standardization and regimentation of farming, slaughtering and processing procedures. Elements of the system are breeding infrastructures, including breeds of pig, breeding and crossing pattern; commercial feed (dried corn with wheat), feeding periods and slaughter weights; methods for slaughtering, cutting, and dressing; and the criterion for testing and grading. The standardization of these procedures enabled mass-production of homogenized pigs and pork.

The grading system I examine is a prime example of standardization through vision, or visual inspection. In 1975, the Japan Meat Grading Association (Nihon Shokuniku Kakuduke Kyokai) established the quality criteria of meat throughout Japan in order to facilitate fair trade of and set appropriate prices (Shokuniku Tsushinsha ed. 2002: 12). A grader is in charge of this task on site in each slaughterhouse.

Graders rank carcasses (eda-niku) on a five part scale after slaughtering and primary-dressing. After a worker has cut off the head from the body, taken out all the internal organs except the kidneys, and split the body vertically with an electric saw grader assess the carcass according to its appearance.

Grading a carcass is a skill that requires both accuracy and speed. A grader needs to manage hundreds of carcasses a day and to judge accurately one after another along a moving line in a few seconds. A pig carcass is judged by set evaluation standards (buta edaniku torihiki kikaku) (Shokuniku Tsushinsha ed. 2002: 12-13). This system enables a grader to judge the quality of the carcass in a moment. The criterion consists of five main items; backfat thickness, sex, width and shape (size), color and shine of flesh and fat (See Table 1).

Backfat thickness is a major determinant of meat grade judgment. Neither too thick nor too thin receives a high rating. Indeed, the visual register of fat thickness is a more important factor than any other. It is also vital that meat itself keeps a good balance between fat and lean. The grader checks weight on a scale but the fat thickness is judged by sight and an "adequate" amount of fatness is formulated minutely.

$\mathrm{S} /$ he also pays close attention to the color of the carcass. It is thought that quality failure appears in discoloration of flesh and fat. Conversely, better quality meat shows through in a shine of color. The textual attributes attributed to the meat are judged by the visual color. That is to say, in this grading system a carcass is not judged by taste and flavor directly but by its appearance such as color alterations, discolorations and a range of shadings and shines. Graders 
depend on sight to grade meat quality and clearly this kind of evaluation system is premised on the presumed higher reliability of the sense of vision over anything else.

TABLE 1

A COMPARISON OF DIFFERENT GRADES

\begin{tabular}{|c|c|c|c|c|c|}
\hline Grades & $\begin{array}{c}\text { Backfat } \\
\text { Thickness }\end{array}$ & Type of Pig & $\begin{array}{c}\text { Width of } \\
\text { Chest }\end{array}$ & $\begin{array}{c}\text { Size of } \\
\text { Rump }\end{array}$ & $\begin{array}{c}\text { Color and } \\
\text { Shine }\end{array}$ \\
\hline High & Thin & For meat & Short & Big & Light \\
\hline Low & Thick* & For breeding & Long & Small & Dark \\
\hline
\end{tabular}

* Fat that is too thin is also graded low.

The grader glances over the whole carcass and ticks off five items one by one with a short glimpse. The grader's primary task is to classify the carcass into a simple five point system; to enable a carcass to be judged nearly automatically, without careful examination or artisanal skills. On this point, we can find an outstanding difference between this kind of judgment and that of a connoisseur.

There is clearly a major gap when compared to the past. Before the grading system started, meat quality related to price was decided by negotiation with a distributer and slaughterer $(w \bar{a}-$ $s \bar{a}$ ) (Yoshida 1983). Pig farmers often said that the negotiation worked in the $w \bar{a}-s \bar{a}$ 's favor due to his superior skill. $W \bar{a}-s \bar{a}$ was a man of authority in handling pigs effectively. Bargaining and evaluation depended on the personal relationship between the $w \bar{a}-s \bar{a}$ and the pig farmer. Thus, this sort of evaluation measure varied considerably because of its inherent and interpersonal flexibility, uncertainty and unpredictability according to time and circumstances. In contrast, however, within the currently existing grading system there is no opportunity to approach graders directly and the criteria for meat evaluation have been fixed and standardized.

I suggest that this fixed criterion of evaluation results in standardization of the commodity. It is notable that the value of the commodity is dominated by vision. In other words, the grading system is guaranteed by the "objectivity" of visual sight. In this respect, we can argue that commodity is visually standardized. As a result, the grading system as a visual-standardizing device enables mass-production and distribution. In what follows, the visual standardization of commodity enters an interesting phase when it is encountered by consumers.

\section{Visually-Dominated Breed Selection}

This section of the article focuses on the sensory aspects of homogenizing pork products. I refer to the homogenization and standardization of the pigs themselves, resulting from the promotion of mass-production.

First, for the sake of mass-production during postwar industrialization, the shape of the pigs was itself altered. Below I explain pig selection for mass-production from the point of the senses. During the processes of postwar re-construction and the industrialization that followed, pig breeds have significantly changed on three occasions.

In the first period, there were indigenous pigs ( $w \bar{a}$ or ag $\bar{u})$ which survived the ravages of war. 
They provided the ground for the propagation of the industry right after the war. The second period arrived when the US Military Government started to introduce various pigs of foreign origin in order to revive the pig-producing system and increase pig propagation they subsequently established a protection policy for indigenous pigs that had survived the ravages of war (Okinawa-ken Norin Suisan Gyoseishi Henshu Iinkai 1986: 255-256; Toyama 1979: 118119). The third period is marked by the rise of the Landrace breed, which subsequently superseded any other species (Toyama 1979: 124-125), and which remains popular. Each of type of pig has its own outstanding characteristics of frame and meat quality (See Table 2) as well as appearance such as hair color, length and size of the body, the proportion of fat and lean meat. Each also differs in rates of fertility and growth.

The native pig is black-haired, stout, and pot-bellied with thick fat. It is superior in terms of its high nursing ability and endurance to subsist on poor feed, but it is inferior in fertility (farrowing rate and sperm count) and speed of growth. Generally speaking, the native pig is suitable to the natural environment of Okinawa, but is criticized as being inefficient in the midst of ongoing industrial developments. Thus, the indigenous pig was systemically replaced by introduced foreign species and non-native pigs appeared throughout Okinawa.

The Landrace breed was introduced in about 1964 (Toyama 1979: 124-125; Yoshida 1983: 47-48). It is more fertile than any other foreign species and has a long life span because of its strong legs which are essential for propagation. In these regards, it has come to be the pig best suited for mass-production. It proliferated and became popular in the 1970s. This was also the exact time, as stated in the second section, that people tried to increase the number of pigs in scale with labor and quality specialization. Landrace, which informants claim combined the best properties of what people desired, was imported into Okinawa and spread quickly. People exclusively chose Landrace for commercial use throughout Okinawa. That is to say, there is a convergence with the arrival of Landrace and the resulting homogenization of pork products. Because Landrace were mass-produced, meat from Landrace is distributed in large quantities.

TABLE 2

THE CHARACTERISTICS OF PIG BREEDS

\begin{tabular}{|c|c|c|c|}
\hline \multicolumn{2}{|r|}{ Items } & $\begin{array}{l}\text { Native Pig } \\
(W \bar{a} \text { or } A g \bar{u})\end{array}$ & Foreign Pigs \\
\hline \multirow{3}{*}{ Appearance } & Hair Color & Black & White \\
\hline & Size of Body & Small $* 1$ & Large $*^{2}$ \\
\hline & $\begin{array}{l}\text { Proportion of Fat } \\
\text { and Lean Meat }\end{array}$ & $\begin{array}{c}\text { Fat } \\
\text { Thick Fat }\end{array}$ & $\begin{array}{l}\text { Lean } \\
\text { Thin Fat }\end{array}$ \\
\hline \multirow{2}{*}{ Efficiency } & Fertility & Low & High \\
\hline & Growth Rate & Low & High \\
\hline
\end{tabular}


The efficiency-oriented selection of pig breeds also changed local tastes; a qualitative transformation of people's preferences occurred. Landrace pigs were supposed to satisfy the needs of efficiency for pig farmers. However, distribution of this meat was not based on the preferences of local people. Locals were now not eating the fatty meat that they were accustomed to, but the leaner meat produced from the Landrace variety of pig.

The point is that the mass-distribution of Landrace pigs created a new taste for different type of pork, and this process homogenized the commodity. Furthermore, convergence on the Landrace breed was reinforced by the introduction of the grading system. The grading system, mentioned earlier in this section, places a special emphasis upon the visual attributes of pork. For this reason, pig farmers need to consider the visual "appropriateness" of their livestock for breeding. Therefore, producers and breeders have singled out the Landrace pig and repeated improvements in an attempt to enhance meat quality. They needed to select this breed because it has thin-layered fat, which raises their prospect of getting higher grade. It is crucial for them to get a higher grade rating because the price of meat ranges dramatically between thirty and forty thousand yen a head. Thus their efforts are directed towards measuring up to a specific level of quality in order to earn the higher ratings and the higher price such a rating commands. Thus, the visual-dominated grading system supports and reinforces efficiency-oriented pig selection and standardized pig varieties.

\section{DIFFERENTIATION OF PIG AND PORK BY MULTIPLE SENSES}

\section{A Revival of the Native Pig}

By the 1980s a movement started to revive and preserve native pigs ( $w \bar{a}$ or $a g \bar{u})$ which had decreased drastically because of the introduction of foreign pigs. In 1981, former museum director Seibin Shimabukuro (Nago-shi 2007; Okinawa-ken Norin Suisan bu Chikusan ka 2007) attempted a head count of the surviving native pigs throughout Okinawa and succeeded in finding only eighteen.

Moreover, this collection of pigs was not purebred but crossbred, hybrids of non-native species, and as such, they were very different in appearance. For this reason, he and his associates carried out an attempt to return crossbred native pigs to their original condition by means of repeated backcrossing as a means to protect the genetic stock. At last in 1993, they have achieved success (Nago-shi 2007).

According to an interview I conducted with a president of association of pig promotion in Okinawa prefecture (Okinawa-ken Yoton Shinko Kyogikai), the revived "indigenous" pig is highly praised for its taste in comparison with foreign ones and its fat is considered especially delicious. In general, however, Okinawan people still tend to prefer lean to fat meat. Thicklayered fat native pigs also tend to get lower grade in the existing grading system. On the contrary, Landrace breeds are guaranteed a higher value by the grading system. However, native pigs are prized due to the thickness of their fat. By this new criterion, when the native pig as commodity differentiated from foreign breeds in taste, its value is boosted and there is a very different set of sensory standards deployed here.

In reviving native pigs, breeders adhered to visual attributes; for example, their black color. Although white-haired native pigs have the same quality of fatty meat, they are not desired. This discrepancy of visual register was also expressed in the local newspaper (Ryukyu Shinpo 2009 May 6th and December 30th). The reason is that whiteness is associated with the Landrace breed, and the new native pig has to be differentiated from foreign pigs, not only in the taste, quantity, 
and quality of its fat but also by its visual appearance (in this case hair color). Therefore, the revival of the native pig means the differentiation of the commodity by sight as well as palate remains.

\section{Sensory Manipulation at the Marketplace}

This section focuses on the sensory processing of pork products at the marketplace (machi$g w \bar{a})$ level. I discuss two cases; one concerns salted pork and the other the large intestine. Both are displayed in an unpackaged condition both inside and outside refrigerated showcases. This mode of display allows customers to touch and hold the pork products directly with their hands and examine them in detail.

\section{Salted Pork}

As mentioned in the second section of this article, salting as a preservation technique was by and large abandoned after home refrigeration became prevalent. Today however, pork is salted as a seasoning and thereby transformed into a product invoking feelings of nostalgia for Okinawans.

In the marketplace, high-grade meat is sold for daily consumption while low-grade meat is generally used during the ritual period (See Table 3). This is because fat thickness is a crucial point for ceremonial meals. There are two varieties of low-graded pork. It is either considered attractive with well-balanced and smooth skin or less attractive with an undulating skin. The former is sold fresh and unprocessed, while purveyors salt the latter to improve its appearance.

Quantities of less attractive products are left unsold during the ritual season because people put greater value on appearance. Okinawan cooking emphasizes the aesthetic aspect of pork dishes. Large blocks of meat are dressed in squares for the formalities of ritual meals. Close attention is paid to the layering of cuts across the grain, and so, bad-looking meat is considered worthless.

TABLE 3

A COMPARISON OF THREE TYPES OF MEAT

\begin{tabular}{|c|c|c|c|}
\hline Meat Type & Use & Cut & Condition \\
\hline High-Graded Meat & Daily Use & Block-cut & Fresh \\
\hline $\begin{array}{c}\text { Low-Graded, Attractive } \\
\text { Meat }\end{array}$ & Ritual Use & Block-cut & Fresh \\
\hline $\begin{array}{c}\text { Low-Graded, Less } \\
\text { attractive Meat }\end{array}$ & Unsalable & Sliced & Salted \\
\hline
\end{tabular}

Salting meat improves its appearance and boosts value. Therefore, purveyors salt for commercial purposes, not preservation. Salted meat does not have to be as attractive because it is sliced thinner. It is interesting that people prefer low-grade meat for rituals, or to put it differently, ritual reverses the rank of the grading system.

\section{The Large Intestine}

As I have explained in greater detail elsewhere (Higa 2008: 77-78), the large intestine (bibi 
or bibi-gwa $)$ is processed at the marketplace. Here I focus on the sensory aspects of processing tripe which is dressed and cleaned in order to promote its multisensory attributes.

During the New Year's season, a large amount of pork and intestines are sold in the marketplace (ibid: 76). Particularly for elderly people, New Year's is nostalgically remembered as extraordinary yearly occasion to eat pork once. The large intestine is the most important ingredient for the ceremonial meals and a large quantity is sold. How much do people consume? A typical small-scale, family-run butcher during in the marketplace sells more than $100 \mathrm{~kg}$ a day of the large intestine during the New Year's season. Thus, the sales during the week equal about $700 \mathrm{~kg}$ of the large intestine, or another way to think about is the intestines of about 583 head of swine (ibid: 76).

Before entering the marketplace, the large intestine is sterilized by boiling it. After this it goes through a sanitary inspection and is then packed at the abattoir for shipment to the market. It is distributed to the marketplace through wholesalers. After arriving in the marketplace, the intestines which have already undergone the same primary processing are again "reprocessed" carefully by butchers. In the course of reprocessing, sellers take account of sensory attributes such as color, scent, texture and taste. To be specific, sellers scrutinize the smell, and feel of the large intestines, one by one, before starting to reprocess them. Depending on the product's condition, they choose adequate procedures for processing (See Table 4).

If it has a bad texture from grittiness and dryness, sellers will soften and smooth it by submerging it in cold running water and stepping on it while they wash it. After washing it, they observe the color. They whiten the large intestine if yellow or spotted by boiling it with baking powder. Customers dislike colored intestines, and therefore white ones are more valuable.

TABLE 4

PROCESSING SENSORY ATTRIBUTES OF THE LARGE INTESTINE

\begin{tabular}{|c|c|c|c|c|}
\hline \multirow{2}{*}{ The Senses } & \multirow{2}{*}{ Attributes } & \multirow{2}{*}{ Problems } & \multicolumn{2}{|c|}{ Processing } \\
\hline & & & Purpose & Method \\
\hline \multirow{2}{*}{ Touch } & \multirow{2}{*}{ Textures } & Grittiness & \multirow{2}{*}{$\begin{array}{c}\text { Softening and } \\
\text { Smoothing }\end{array}$} & \multirow{2}{*}{$\begin{array}{l}\text { Washing and } \\
\text { Stepping }\end{array}$} \\
\hline & & Dryness & & \\
\hline \multirow{2}{*}{ Sight } & \multirow{2}{*}{ Colors } & Yellow & \multirow{2}{*}{ Whitening } & \multirow{2}{*}{$\begin{array}{l}\text { Boiling with } \\
\text { Baking Power }\end{array}$} \\
\hline & & Spotted & & \\
\hline Smell & Odors & Bad smell & Deodorizing & $\begin{array}{c}\text { Removing bad- } \\
\text { smelling portions } \\
(\text { abura })\end{array}$ \\
\hline
\end{tabular}

The hardest and most important work is eliminating any bad smells emitted from the large intestines. It is necessary to peel off the fatty film and other oleaginous matter called abura. This work is said to be effective in deodorizing it, but it takes a great deal of time and patience. Two hours are required to re-process only ten kilograms of the product. Moreover, after peeling, the quantity is reduced. Reprocessed ten kilograms becomes seven kilograms. Although in theory $30 \%$ in profit is lost, this is a necessary procedure. Peeled large intestines have a better reputation 
and higher value and are considered marks of distinction related to particular butcher stalls. Contrary to this specialized processing, supermarkets sell them unpeeled. For this reason, many customers will travel by bus to remote areas to buy the peeled products so that they will not have to do it themselves.

Customers value the large intestine in different ways depending on the generation to which they belong. Younger generations are interested in its color and seek whiter intestines that look clean and fresh. By contrast, elderly customers tend to be interested in smell and always sniff the large intestine to judge its qualities when buying. They put a special emphasis on scent to detect any defects, such as residual fecal matter. For this reason, sellers expend laborious efforts to remove any distasteful smells.

Comparing the generations, differences in the use of the senses are obvious. While elders care about the olfactory dimensions, the younger customers look for visual colors. Therefore sellers have developed methods of multisensory manipulation in re-processing the large intestine. And in this way, yet again, sensual values differentiate the commodity.

\section{Multisensory Differentiation}

The three cases in this section can be divided into two categories related to stages of meat processing place. One stage of production takes place on the pig farm, the other stage is the downstream market or the consumption region marketplace. Thus, pigs are processed in the primary stage and, pork and intestines are reprocessed in the secondary stage. Moreover, these three cases, pig-to-pork-to-intestine, are similar with respect to the sensory values enriched, but vary in ways that their value as a commodity is increased. The cases of revived native pigs and salt pork involve differentiation by sight and palate from standardized pigs and pork. In contrast, the large intestine is differentiated by sight, smell and touch from the "dirty" intestines.

In the case of pork, meat estimated low in the grading system is raised in value by altering its appearance and taste. There is a value conversion brought about by transforming the evaluation standard of the present into the register of the nostalgic past. With intestines, sellers clean and beautify them by whitening, deodorizing and smoothing them. Since unclean intestines evoke the pigs' living habits, sellers try to remove the dirtiness in order to increase its value. These procedures make it distinct from unpeeled, mass-produced intestines sold at supermarkets. In all of these scenarios there is differentiation of the commodity by the multisensory manipulation.

\section{THE CULTURAL CODE BEHIND THE SENSORY MANIPULATION}

Some cases of the homogenization and differentiation of pigs and pork have been discussed in the previous sections. Therefore, this section highlights how the cultural code from the commoditization process adding to the sensory value of pigs and pork can be extracted. I introduced the grading system as a case of homogenization by vision. The evaluation standard judges meat quality by the appearance of backfat thickness. I outlined how this process is highly dependent on the graders' sense of vision. This newer institution is slightly different from that of the past in Okinawa when distributers and slaughterhouses used to decide meat prices by direct negotiation with pig farmers. However, as discussed above, this form of transaction was abandoned in order to establish a more efficient production system. Thus, a division of labor emerged whereby invisible, anonymous graders came to decide prices.

Next, I discussed pig selection. The need for efficiency led to a convergence of pigs with improved fertility abilities with the resulting homogenization of both pigs and pork, alongside 
the rapid decrease in numbers of the native Okinawan pig species. This was reinforced by the grading system, which is advantageous for producers of thin-fat foreign pigs. The focus on producing non-native pigs has accelerated. And, as a result, a series of visual-centered homogenization regulations prompted by the desire for efficiency in production has resulted in transforming the consumers' palate and sight.

The third case is a revival of the native pig in reaction to the prevalence of foreign breeds. Native pigs are differentiated from foreign pigs by their hair color and the tastiness of their fatty meat. The former inferiority of fattiness evaluated by the grading system has now become superior to foreign fatless meat. Above, salt pork was also examined. Salting was a common domestic preserving technique until refrigeration technology was introduced to Okinawa. However, salting is now used for different purposes, for example as a dressing technique for visually unappealing meat. Sellers try to improve and boost the value of bad-looking meat through salting. For consumers, the new version of salt pork has a good flavor and evokes the nostalgic memories of the past. In this way, new salted pork is superior to more attractive cuts of meat as determined by the visual-centered grading system.

Finally, I discussed the large intestine and its role as the most important ingredient in ceremonial meals. At the marketplace, the intestine undergoes elaborate reprocessing. Sellers try to whiten, deodorize and smooth it in order to boost its value. The most important procedure is deodorization which is accomplished through peeling off an outer fatty layer. Peeled intestines are more valuable than the unpeeled ones which are commonly sold in supermarkets. In sum, reprocessing differentiates this product from mass-distributed unprocessed products and this is one example of multisensory differentiation.

These phenomena of different modes of differentiation should be understood within the cultural code of Okinawa. Until the 1970s, the production and consumption of pig products were embedded in a subsistence economy. Pork was not consumed regularly, and pigs were killed only in the context of rituals. A high value was placed on fat. Recent industrialization has changed the lifestyle of average Okinawan's considerably. However, fatty native pigs, and indexical marker of 'typified' culture are being revived. Additionally, the high-grade thin-fat pork of foreign pigs is accepted for daily meals, while the fatty meat of native pigs, though ranked low in the grading system, is now regarded proper and valuable for ceremonial meals and thus commands a higher commercial value. In this way, the multisensory differentiation of commodity is motivated by enduring cultural meanings. That is to say, pork is localized within the cultural code set against the visual standardization of pork as a commodity in mass production.

\section{CONCLUSION}

We have seen how the commoditization of pork is deeply involved in the bodily senses. This is a striking feature of industrialized Okinawan food (See Figure 1). Through the example of the grading system and pig selection, I have outlined how pigs and pork products are distributed in wider areas than before in Okinawa. In this system pigs and pork are homogenized visually. But the homogenized pigs and pork products are again differentiated by multiple senses, as illustrated in this article with several examples; the resurgence of native pigs, salt pork and intestines at the local marketplace. In my case studies, food is processed and also evaluated by the shared senses of both the producer and the consumer. 


\section{FIGURE 1}

\section{THE CHARACTERISTICS OF FOOD PRODUCTS IN INDUSTRIAL SOCIETIES}

\begin{tabular}{|ll|}
\hline \multicolumn{1}{|c|}{ Macro Level } & \multicolumn{1}{c|}{ Micro Level } \\
\hline & \\
Distribution in & Distribution to Local \\
Wide-range & Marketplace \\
Homogenization by & Differentiation by \\
Vision & Multi-senses \\
\hline
\end{tabular}

People in Okinawa tend to emphasize their continuity of pork consumption throughout the island's history. They maintain the native pig and sell salt pork and intestines at the marketplace. The color, shape and scent of pig and pork suits their preferences well. However, as stated above, these products are newly created by both visual-centered homogenization and multisensory differentiation. Therefore, these complicated processes of commodification are configured through the apparent continuity of pork consumption in the context of Okinawa's pork industry. This means that adding sensory values to a commodity leads to a cultural reproduction and the differentiation of goods not propelled by market forces but by a localized cultural code. Thus commodity production is accompanied by a reproduction of a culture.

As McLuhan pointed out (McLuhan 1962), visual sight predominates the apparatus of perception in modern societies. The standardization of food is indeed grounded on the reliability of vision in my cases, yet by turning to the local market place, we are able to better comprehend the dynamics of human multi-senses embodying a local cultural code.

\section{REFERENCES}

Bestor, Theodore (2001). Supply-Side Sushi: Commodity, Market, and the Global City. American Anthropologist_102(1), 76-95.

(2004). Tsukiji: The Fish Market at the Center of the World. California: University of California Press.

Counihan, Carole (1999). Anthropology of Food and Body: Gender, Meaning and Power. New York and London: Routledge.

Classen, Constance, David Howes, and Anthony Synnott (1994). Aroma: The Cultural History of Smell. New York and London: Routledge.

Goody, Jack (1982). Cooking, Cuisine and Class: A Study in Comparative Sociology. Cambridge: Cambridge University Press.

Grasseni, Cristina 2003 Packaging Skills: Calibrating Cheese to the Global Market. In Susan Strasser (ed.) Commodifying Everything: Relationships of the Market. pp. 259-288. New York and London: Routledge. 
(2005). Slow Food, Fast Genes: Timescapes of Authenticity and Innovation in the

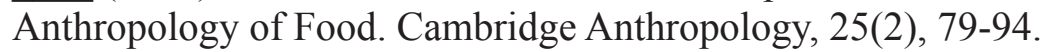

Green, Bill (2002). Introduction: Human Factors and Design. In William S. Green and Patrick W. Jordan (eds.) Pleasure with Products: Beyond Usability, pp.1-5. London and New York: Taylor and Francis.

Kinjo Sumiko (1987). Okinawa no Nikushoku Bunka ni kansuru ichi Kosatsu: Sono Hensen to Haikei (An Analysis of Meat-Eating Culture in Okinawa: Changes and Backgrounds). Seikatu Bunka-shi , 11, 14-30.

Komatsu Kaori (2007). Zairai Kachiku no Shohinka: Okinawa Zairai-ton “Agu” no Fukkatsu (Commodification of Native Domesticated Animal: Revival of Okinawan Indigenous Pig "Agū"). In Kawai Kaori (ed.) Ikiru ba no Jinruigaku. pp.365-385. Kyoto: Kyoto Daigaku Gakujutsu Shuppankai.

Hagiwara Sahito (1995). Butaniku no Bunrui, Ryori, Girei-jo (Classification, Cuisine and Ritual of Pork). Rekishi Jinrui 23, 119-140.

(2009). Nikushoku no Minzokushi (Folklore of Meat Consumption). In Furuie Shinpei, Oguma Makoto, and Hagiwara Sahito (eds.) Nihon no Minzoku Jüni pp.195-278. Yoshikawa Kobunkan.

Higa Rima (2008). Gendai Okinawa ni okeru Butaniku no "Bubun-Shohi" no Kakudai to Seigyo: Shokuniku Ryutsu no Kindaika ni Shoten wo atete (Increasing and Controlling the "Partial Consumption" of Pork in Contemporary Okinawa: Focusing on Modernization of Pork Distribution). Intercultural 6, 66-83.

Howes, David (2005). Hyperesthesia, or, The Sensual Logic of Late Capitalism. In David Howes (ed.) Empire of the Senses: The Sensual Culture Reader. pp.281-303. Oxford: Berg.

McLuhan, Marshall (1962). The Gutenberg Galaxy: The Making of Typographic Man. Toronto: University of Toronto Press.

Nago-shi (2007). Shimin no Hiroba (Citizen Square). Newsletter of Nago City 430. Nago-shi.

Okinawa-ken Norin Suisan bu Chikusan ka (2007). Ryukyu Zairai-ton Agu Monogatari: Okinawa Brand-ton Sakushutu heno Michi (A Film of Ryukyu Native Pig Agū: A Way to Produce Okinawan Brand Hog). Okinawa-ken Norin Suisan bu Chikusan ka.

Okinawa-ken Norin Suisan Gyoseishi Henshu Iinkai (1986). Okinawa-ken Norin Suisan Gyoseishi Dai-go-kan Chikusan Yosan hen (Okinawan Administrative History of Agriculture, Forestry and Fisheries: Fifth Volume of Livestock-Breeding and Sericulture). Norin Tokei Kyokai. 
Ohnuki-Tierney, Emiko (1997). McDonald's in Japan: Changing Manners and Etiquette. In James Watson (ed.) Golden Arches East: McDonald's in East Asia. pp.161-182. Stanford: Stanford University Press.

Rajagopal, Arvind (1998). Advertising, Politics and Sentimental Education of the Indian Consumer. Visual Anthropology Review, 14(2), 14-31.

Ryukyu Seifu Bunkyokyoku (1988). Ryukyu Shiryo Dai-roku-shu Keizai hen (Historical Documents of the Ryukyu: Sixth Volume of Economy). Naha Shuppansha.

Ryukyu Shinpo (Newspapers) (2009). March 6th, December 30th.

Sahlins, Marshall (1976). Culture and Practical Reason. Chicago and London: The University of Chicago Press.

Seremetakis, C. Nadia (1994). The Memory of the Senses, Part1: Marks of the Transitory. In C. Nadia Seremetakis (ed.) The Senses Still: Perception and Memory as Material Culture in Modernity. pp.1-18. Chicago and London: The University of Chicago Press.

Shimabukuro Seibin (1989). Okinawa no Buta to Yagi: Seikatsu no naka kara (Pigs and Goats in Okinawa: In Everyday Lives). Hirugisha.

Shokuniku Tsushinsha ed. (2002). Buta Eda-niku no Bunkatsu to Cutting: Butaniku wo Shohinka surumade (Cutting Pork Carcass: Commodification of Pork Meat). Shokuniku Tsushinsha.

Sutton, David (2001). Remembrance of Repasts: An Anthropology of Food and Memory. Oxford: Berg.

Toyama Shinshu (1979). Okinawa-ken Chikusan Shi (A History of Animal Husbandry in Okinawa Prefecture). Naha Shuppansha.

Yoshida Shigeru (1983). Koiki Ryutsu Kankyo-ka ni okeru Buta no Chiiki-nai Jikyu Ryutsu Kozo ni kansuru Kenkyu: Okinawa-ken ni okeru Buta Ryutsu no Tokushitu to sono Keizaiteki Igi (A Study of Pork Self-Sufficient Distribution Structure in an Extensive Distribution:

Characteristics and Economic Meaning of Hog Distribution in Okinawa Prefecture). Ryukyu

Daigaku Nogaku-bu Gakujutu Hokoku, 30, 1-123.

\section{ACKNOWLEDGEMENTS}

This article is based on a presentation at the Fourth Workshop on the Encounters of Young Scholars on Asian Studies in January 2011 at the University of Hong Kong. I would like to thank Dixon Wong Heung Wah for giving me this opportunity to participate in this workshop. I wish to thank Adam Lebowitz of the Foreign Language Center, University of Tsukuba, for his assistance in preparing this article. I received advice from Keiji Maegawa, Paul Hansen and Hiroki Fukagawa at University of Tsukuba and John Mock at Temple University. I would like to thank them. This field research was supported by grants from Inter Faculty Education and Research Initiative (IFERI) at University of Tsukuba and Shibusawa Minzokugaku Shinkō Kikin (Shibusawa Foundation for Promotion of Ethnology). 